\title{
Effects of Tree Species on Root Exudation and Mineralization of Organic Acids in a Tropical Forest
}

\section{Kazumichi Fujii ( $\nabla$ fkazumichi@affrc.go.jp )}

Forestry and Forest Products Research Institute https://orcid.org/0000-0001-9883-8044

\section{Chie Hayakawa}

Utsunomiya University

\section{Sukarti Ningsih}

Mulawarman University

\section{Research Article}

Keywords: Decomposition, Organic acid, Phosphorus deficiency, Sorption, Tropical forest

Posted Date: June 7th, 2021

DOl: https://doi.org/10.21203/rs.3.rs-544741/v1

License: (1) This work is licensed under a Creative Commons Attribution 4.0 International License. Read Full License 
$6 \quad{ }^{1}$ Forestry and Forest Products Research Institute, Tsukuba 305-8687, Japan

$7 \quad{ }^{2}$ Faculty of Agriculture, Utsunomiya University, Utsunomiya 321-8505, Japan

$8 \quad{ }^{3}$ Faculty of Forestry, Mulawarman University, Samarinda 75123, East Kalimantan, Indonesia

9

10 Running title: Effects of tree species on root exudation

11

12 * Correspondence: K. FUJII, Forestry and Forest Products Research Institute, Matsunosato 1, 13 Tsukuba, Ibaraki, 305-8687, Japan. Tel: +81-29-829-8228; Fax: +81-29-873-1542.

14

E-mail: fjkazumichi@gmail.com (K. Fujii)

16

17

18

19

20

21 
Abstract

23 Aims Root exudation of organic acids is one of strategies for tropical trees to facilitate nutrient

24 uptake from the highly weathered soils. However, paradoxical relationship remains that root

25 exudation also stimulates microbial activities to consume organic acids in the rhizosphere (root-

26 soil interface). Plant-specific root exudation might shape different rhizosphere carbon (C) cycles

27 between tree species. We test whether root exudation and rhizosphere $\mathrm{C}$ fluxes of organic acids

28 and sugars differ between dominant dipterocarp trees and pioneer trees (Macaranga spp.).

Methods We measured (1) root exudation from mature trees, (2) soil solution concentrations of organic acids and monosaccharides, and (3) mineralization kinetics of ${ }^{14} \mathrm{C}$-radiolabelled substrates in the rhizosphere and bulk soils of the Dipterocarp and Macaranga trees.

Results Malate was a dominant organic acid exuded from Dipterocarp roots, while monosaccharides were dominant exudates of pioneer Macaranga trees. Malate exudation rates by Dipterocarp roots were greater compared to Macaranga roots. Organic acid exudation increased with increasing root surface area and with decreasing soil $\mathrm{pH}$. Microbial activities of malate mineralization were enhanced in the rhizosphere both under Dipterocarp and Macaranga trees, but the $\mathrm{C}$ fluxes of malate mineralization by rhizosphere microbes far exceeded root exudation due to microbial malate production in the rhizosphere of Dipterocarp trees. Conclusion Tree species develop different strategies to increase malate concentration in rhizosphere soil directly through root exudation or indirectly through rhizosphere microbial activities to increase malate production, which is favorable for phosphorus solubilization, 
aluminum detoxification, and lignin degradation in acidic soils.

44 Key words: Decomposition; Organic acid; Phosphorus deficiency; Sorption; Tropical forest

\section{Introduction}

In the tropical forests, long-term weathering and acidification of soils generally result in a decrease in available phosphorus (P) (Walker and Syers, 1976). This is hypothesized to cause a decline in biomass productivity (Wardle et al., 2004), but high productivity could be maintained by plant species diversity and habitat differentiation (Fujii et al., 2018). There should occur a variety of belowground strategies of tropical tree species to acquire nutrients from the highly weathered soils (Fujii et al., 2018; Ma et al., 2018).

The soil in the vicinity of fine roots, termed as rhizosphere, is a hotspot for carbon (C) and nutrient cycles (Kuzyakov and Razavi, 2019). Root exudation of low molecular weight organic acids (LMWOAs) such as oxalic, citric, and malic acids, can increase in response to P deficiency to solubilize recalcitrant $\mathrm{P}$ bonded with aluminum or iron oxides (Jones, 1998). Although the concentrations of LMWOAs are generally low in soil solution (Strobel, 2001), they increase towards root surface due to the localized substrate inputs (Jones et al., 2004). Root exudation of labile substrates increases the biomass and/or activity of rhizosphere microorganisms and promotes nutrient cycles through priming effects (Dijkstra et al., 2013). However, there was a paradox that root exudation increases microbial activity to consume exuded LMWOAs in the 
rhizosphere (Fujii et al., 2013). Organic acids can also be consumed through sorption onto the solid phase (Ström et al., 2001). Mineralization and sorption risk under/overestimating the efficacy of the exuded LMWOAs in rhizosphere processes (Jones et al., 2003).

Diverse plant roots release different kinds and amounts of low molecular weight organic substances (LMWOSs; LMWOAs and sugars) in tropical forests (Grayston et al., 1996; Aoki et al., 2012). The decomposability of LMWOS and extent of sorption are compound-specific (Jones and Brassington, 1998; Ström et al., 2001; Van Hees et al., 2003). Microbial community grown in presence/absence of LMWOAs tends to increase/decrease transporter activity and dependency of LMWOAs for microbial respiration (Jones et al., 1996; Fujii et al., 2019). When a certain tree species releases specific root exudates, rhizosphere microbes might induce a shift towards specializer of root exudates and re-shape rhizosphere $\mathrm{C}$ and nutrient cycles. The importance of these direct and indirect effects in rhizosphere or whole soil C cycles has rarely been quantified. Bornean primary forest accommodates dominant species (Dipterocapus cornutus and Shorea laevis) and pioneer species (Macaranga gigantea) that differ in terms of root morphology (e.g., ectomycorrhizal finer roots vs. non-ectomycorrhizal coarser roots). The greater aboveground biomass and longer lifespan of dipterocarp trees, compared to Macaranga trees, should require greater amounts of organic acid exudation to solubilize $\mathrm{P}$ and detoxify $\mathrm{Al}^{3+}$ and have mechanisms to maintain high levels of organic acids in the rhizosphere. We hypothesized that root exudation and rhizosphere LMWOS-C fluxes could differ between contrasting tree species.

81 Here, we tested (1) whether composition and amounts of root exudation differ between 
dominant dipterocarp trees and pioneer trees, (2) whether different root exudates cause

83 specialization of substrate mineralization by rhizosphere microbes, and (3) whether root

84 exudation and rhizosphere $\mathrm{C}$ fluxes are quantitatively important relative to the bulk soil C cycles.

\section{Materials and Methods}

\section{Site description}

Experiments were carried out in tropical forests and agroecosystems in Bukit Soeharto ( $\mathrm{S} 0^{\circ} 51^{\prime}$,

E11706'; 99 m a. s. 1., average inclination $15^{\circ}$ ), East Kalimantan Province, Indonesia (Fig. 1).

After the fires in 1982-1983, we established five plots $(20 \mathrm{~m} \times 20 \mathrm{~m})$ of undisturbed primary

dipterocarp forest dominated by Dipterocapus cornutus and Shorea laevis and natural secondary

forest with regeneration by pioneer species Macaranga gigantea, respectively. The mean annual air temperature was $26.8^{\circ} \mathrm{C}$, and the mean annual precipitation was recorded as $2187 \mathrm{~mm} \mathrm{yr}^{-1}$.

Soils were derived from sedimentary rocks and classified as Typic Paleudults (Soil Survey Staff, 2014). The detailed features of these sites and soil properties are described in Fujii et al. (2020).

\section{Soil sampling}

The composite soil samples were collected from three pits at each plot in August 2012. The distance between each pit was $10 \mathrm{~m}$. The surface mineral soil horizons (A horizon; 0-10 $\mathrm{cm}$ ), where roots and microbial activities are considered to be high, were collected and analyzed (Table 
102 fresh soil samples were separated into rhizosphere and bulk fractions. Rhizosphere soil fractions

103 were obtained by collecting the soil materials adhering closely to roots, after gently shaking the

104 fine root systems (diameter $<2 \mathrm{~mm}$ ) 10 times until the loosely adherent soil was removed. The

105 bulk fractions were collected from the soil outside the rooting area. After removing rhizosphere

106 soil, roots were washed and scanned in a flat screen scanner (GT-S600, EPSON, Tokyo, Japan),

107 and the root surface area and root tip number were analyzed using Win-Rhizo (Regents

108 Instruments Inc., Quebec, Canada). The thickness of the rhizosphere soil was calculated by

109 dividing the volume of the adherent soil by the root surface area. The percentage of the

110 rhizosphere soil relative to the total mass of soil was calculated from the thickness of the

111 rhizosphere soil, root surface area, and bulk density.

112

\section{Physicochemical analysis of soils}

114 A proportion of the fresh soil samples were air-dried and sieved $(<2 \mathrm{~mm})$ to eliminate litter, roots

115 and pebbles. Soil $\mathrm{pH}$ was measured using a soil to solution $\left(\mathrm{H}_{2} \mathrm{O}\right.$ or $\left.1 \mathrm{M} \mathrm{KCl}\right)$ ratio of 1:5 (w/v)

116 after shaking for $1 \mathrm{~h}$. Total $\mathrm{C}$ and $\mathrm{N}$ concentrations were measured using a $\mathrm{CN}$ analyzer (Vario

117 Max CN, Elementar Analysensysteme GmbH). Particle size distribution [clay $(<0.002 \mathrm{~mm})$; silt

$118(0.002-0.05 \mathrm{~mm})$; sand $(0.050-2 \mathrm{~mm})]$ was determined using the standard sedimentation method.

119 The available phosphorus (P) concentrations were estimated using the Bray 2 extraction method

120 (Blakemore et al., 1987).

121 
123 The centrifugation-drainage technique was used to extract soil solution (Giesler and Lundström,

124 1993). Without addition of water, the rhizosphere and bulk soil fractions were centrifuged for 30

$125 \mathrm{~min}$ at a speed of $8,800 \mathrm{rpm}(10,560 \mathrm{~g} ; \sim 1.5 \mathrm{MPa}$; Hitachi centrifuge) within $36 \mathrm{~h}$ of sampling,

126 respectively. The soil solution extracts were filtered through a $0.6 \mu \mathrm{m}$ filter (GF/C, Whatman) and

127 frozen at $-24^{\circ} \mathrm{C}$ prior to analysis. The monosaccharide concentrations were determined using

128 periodate oxidation (Burney and Sieburth, 1977; Johnson and Sieburth, 1977) and glucose

129 standards. The concentrations of LMWOAs were determined by high performance liquid

130 chromatography (HPLC, Shimadzu, Japan) using the method by Van Hees et al. (1999). Organic

131 acids were separated on a Supelcogel $\mathrm{C} 610-\mathrm{H}$ ion exclusion column using $0.1 \% \mathrm{H}_{3} \mathrm{PO}_{4}$ as the

132 mobile phase at operating temperatures of $60^{\circ} \mathrm{C}$ for citric acid and $30^{\circ} \mathrm{C}$ for oxalic and malic acids

133 with UV detection at $210 \mathrm{~nm}$.

135 Organic acid and glucose mineralization kinetics

136 As previously outlined in our previous study (Fujii et al., 2019), C fluxes of LMWOS in soils

137 were estimated for the rhizosphere and bulk soil fractions. ${ }^{14} \mathrm{C}$-radiolabelled glucose or organic

138 acid solution $\left(100 \mu \mathrm{L}\right.$; specific activity: $\left.0.17 \mathrm{kBq} \mathrm{mL}^{-1} ; \mathrm{pH} 4.5\right)$ was added to $1 \pm 0.02 \mathrm{~g}$ of field-

139 moist soil in 50-mL polypropylene vials. ${ }^{14} \mathrm{C}$-glucose $\left(\mathrm{U}-{ }^{14} \mathrm{C}\right.$; American Radiolabeled Chemicals,

140 Inc., $\left.0.4 \mathrm{GBq} \mathrm{mmol}{ }^{-1}\right)$ and four organic acids, ${ }^{14} \mathrm{C}$-acetic acid $\left(1,2-{ }^{14} \mathrm{C} ; 2.2 \mathrm{GBq} \mathrm{mmol}{ }^{-1}\right),{ }^{14} \mathrm{C}$ -

141 oxalic acid $\left(1,2-{ }^{14} \mathrm{C} ; 0.2 \mathrm{GBq} \mathrm{mmol}^{-1}\right),{ }^{14} \mathrm{C}$-malic acid $\left(1,2-{ }^{14} \mathrm{C} ; 0.2 \mathrm{GBq} \mathrm{mmol}^{-1}\right)$, and ${ }^{14} \mathrm{C}$-citric 
142 acid $\left(1,5{ }^{14} \mathrm{C} ; 2.2 \mathrm{GBq} \mathrm{mmol}^{-1}\right)$, were used in the mineralization assays. The initial solution

143 concentrations of each substrate were 50, 250, 500, and $1000 \mu \mathrm{M}$. Following addition, the soil

144 was gently shaken to ensure mixing and incubated at $25{ }^{\circ} \mathrm{C}$ in sealed vials. ${ }^{14} \mathrm{C}-\mathrm{CO}_{2}$ produced by

145 mineralization of the added substrate was collected in a plastic scintillation vial containing 1.0

$146 \mathrm{~mL}$ of $1 \mathrm{M} \mathrm{NaOH}$ placed on top of the soil, separated by a spacer. The ${ }^{14} \mathrm{C}_{-}-\mathrm{CO}_{2}$ concentrations

147 trapped in $\mathrm{NaOH}$ were determined by liquid scintillation using alkali-compatible scintillation

148 fluid (Hionic-Fluor; Perkin Elmer). ${ }^{14} \mathrm{C}-\mathrm{CO}_{2}$ production was measured during the initial linear

149 phase of decomposition (1 h), which was confirmed by the pilot experiment.

150 The data of mineralization kinetics were fitted to a single Michaelis-Menten equation:

$151 \quad V=\left(V_{\max } \times C\right) /\left(K_{M}+C\right)$

152 where $V$ is the mineralization rate $\left(\mathrm{nmol} \mathrm{g}^{-1} \mathrm{~h}^{-1}\right), C$ is the substrate concentration $(\mu \mathrm{M})$ in the soil

153 solution, $V_{\max }$ is the maximum mineralization rate $\left(\mathrm{nmol} \mathrm{\textrm {g } ^ { - 1 }} \mathrm{h}^{-1}\right)$, and $K_{M}$ is the concentration at

154 which the half-maximal mineralization rate occurs $\left(1 / 2 V_{\max } ; \mu \mathrm{M}\right)$. Michaelis-Menten plots of

155 organic acids were constructed using the equilibrium organic acid concentrations in soil solution,

156 assuming complete mixing of the organic acid with the intrinsic soil water and the sorption

157 reaction (see the following section).

159 Sorption isotherms of organic acids

160 Glucose is not adsorbed onto the solid phase due to a lack of charge, whereas negatively charged

161 carboxylic acids (acetic, oxalic, malic, and citric acids) are strongly adsorbed onto the solid phase 
162 (Jones and Brassington, 1998). To estimate the equilibrium concentrations of the organic acids in

163 the soil solution after adding organic acid in the kinetic experiments, sorption isotherms were

164 obtained by the method of Fujii et al. (2019). In each tube, $2.5 \mathrm{~mL}$ of ${ }^{14} \mathrm{C}$-radiolabelled organic

165 acid solution (170 Bq mL $\left.{ }^{-1} ; \mathrm{pH} 4.5\right)$ was added to $0.50 \mathrm{~g}$ of chloroform-fumigated (48 h) field-

166 moist soil in $6-\mathrm{mL}$ plastic vials with a soil to solution ratio of 1:5 (w/v). The initial organic acid

167 concentration ranged from 100 to $1000 \mu \mathrm{M}$. Following addition, the samples were shaken for 10

$168 \mathrm{~min}$ on a reciprocating shaker at $320 \mathrm{rpm}$. The samples were subsequently centrifuged $(16,000 \times$

$169 \mathrm{~g}$ for $5 \mathrm{~min}$ ) and the supernatant was recovered. The equilibrium ${ }^{14} \mathrm{C}$ concentrations in solution

170 were determined by liquid scintillation counting (Aloka Liquid Scintillation System, LSC-3050;

171 Hitachi) using Optiphase HiSafe 2 scintillation fluid (Perkin Elmer, Japan).

172 Then, the sorption isotherm data were fitted to the Freundlich equation:

$173 A=k \times C^{1 / n}$

174 where $A$ is the quantity of organic acid adsorbed (nmol $\left.\mathrm{g}^{-1}\right), C$ is the equilibrium solution

175 concentration $(\mu \mathrm{M}), k$ is the Freundlich's constant related to soil ability to sorb organic acid, and

$1761 / n$ is the constant related to sorption intensity. The quantity of anion adsorbed $(A)$ can be

177 calculated using the following equation:

$178 C_{\text {tot }}=(C \times \theta)+(A \times \gamma)$,

179 where $C_{\text {tot }}$ is the total quantity of organic acid added to the soil $\left(\mathrm{nmol} \mathrm{cm}{ }^{-3}\right), C$ is the equilibrium

180 soil solution concentration $(\mu \mathrm{M}), \theta$ is the volumetric water content $\left(\mathrm{cm}^{3} \mathrm{~cm}^{-3}\right)$, and $\gamma$ is the soil

181 bulk density $\left(\mathrm{g} \mathrm{cm}^{-3}\right)$. 
183 The mineralization rates of LMWOSs at their actual substrate availability were estimated using

184 Eq. 1, assuming that LMWOSs in soil solutions are utilized by soil microbes as described by

185 Michaelis-Menten kinetics. Using the bulk density, the volumes of the rhizosphere and bulk soil

186 fractions, the mineralization rates were scaled up to the $\mathrm{C}$ fluxes in the surface soil horizon $(0-10$

$187 \mathrm{~cm})$. The rhizosphere effects $(R)$ were assessed by dividing the rhizosphere $\mathrm{C}$ flux fraction

$188\left[F_{\text {Rhizosphere }}, F_{\text {Bulk }}\left(\mathrm{mmol} \mathrm{C} \mathrm{m}^{-2} \mathrm{~h}^{-1}\right)\right]$ relative to rhizosphere soil mass fraction $\left[M_{\text {Rhizosphere}}, M_{\text {Bulk }}\right.$ $189(\%)]$

$R=\left(F_{\text {Rhizosphere }} / F_{\text {Bulk }}\right) /\left(M_{\text {Rhizosphere }} / M_{\text {Bulk }}\right)$

\section{Quantification of root exudation rates}

193

Root exudates were collected from alive roots of mature trees, according to Phillips et al. (2008).

194 We selected two dominant species (Dipterocapus cornutus and Shorea laevis) in primary dipterocarp forest and one pioneer species (Macaranga gigantea) in Macaranga forest, respectively. The alive fine root systems (diameter $<2 \mathrm{~mm}$ ) were carefully excavated from the soil

197 at the boundary between the organic and mineral soil horizons. After the roots were carefully rinsed with distilled water to remove the adhering soil, the alive root systems were placed in 50 $\mathrm{mL}$ syringes filled with sterile acid-washed glass beads and a C-free solution. After $48 \mathrm{~h}$, the solution containing exudates was collected using another syringe. The experiments were conducted with five replicates for each species. The solutions were filtered through a $0.6 \mu \mathrm{m}$ filter 
202 (GF/C, Whatman) and frozen at $-24^{\circ} \mathrm{C}$ prior to analysis. The concentrations of monosaccharides

203 and acetic, oxalic, citric, and malic acids in the solutions were determined as with soil solution

204 analyses. Rates of root exudation $\left(\mathrm{nmol} \mathrm{g}^{-1} \mathrm{root}^{-1}\right)$ were calculated using the organic acid

205 concentrations $\left(\mathrm{nmol} \mathrm{L}^{-1}\right)$, the quantity of solution in the syringe $(30 \mathrm{~mL})$, and the time between

206 sample collections (48 h).

207

208 Calculations and statistics

209 All results are expressed on an oven-dry $\left(105^{\circ} \mathrm{C}, 24 \mathrm{~h}\right.$ for soil and $70^{\circ} \mathrm{C}, 48 \mathrm{~h}$ for root) weight

210 basis and are the mean \pm standard error (SE) of five replicates. The statistical differences of mean

211 values between groups (tree species, rhizosphere vs. bulk soil fraction) were tested using analysis

212 of variance (ANOVA) at a $P<0.05$ significance level for soil solution concentrations, sorption

213 isotherm parameters, mineralization kinetics parameters, and root exudation rates. The statistical

214 analyses were performed using SigmaPlot 14.0 (SPSS Inc., 2020). The Michaelis-Menten

equation and Freundlich equation were fitted to the mineralization kinetics data and the sorption

isotherm data, respectively, using a least-squares optimization procedure with SigmaPlot 14.0.

The significant differences of the Michaelis-Menten and Langmuir parameters were tested with a modified $t$ - test and the modified Tukey method (Zar, 1999). 
222 Under the Macaranga trees, soil $\mathrm{pH}$ and available $\mathrm{P}$ were higher than under the Dipterocarp trees

223 due to the ash inputs in the past fires (Table 1). There was no difference in microbial biomass C

224 between Dipterocarp and Macaranga forest sites (Table 1). Although Dipterocarp tree roots had

225 larger root surface areas and more root tips (Table 2), the rhizosphere soil was thinner in the

226 Dipterocarp roots (avg. $1.3 \mathrm{~mm}$ ) than in the Macaranga roots (avg. $3.5 \mathrm{~mm}$ ). The rhizosphere soil

227 fraction constituted $5.5 \%$ and $8.3 \%$ of the total soil masses in the Dipterocarp and Macaranga

228 sites, respectively.

\section{Low molecular weight organic substance concentration in rhizosphere and root exudation}

231 Compared to the bulk soil, rhizosphere soil solution displayed significantly higher concentrations

232 of malic and oxalic acids in the Dipterocarp soil (Fig. S1; Fig. 1). No enrichment effects of

233 LMWOAs in the rhizosphere were observed in Macaranga soil (Fig. S1; Fig. 1). There was no

234 significant difference in acetic acid and monosaccharide concentrations in rhizosphere and bulk

235 soil solutions between Dipterocarp and Macaranga sites (Fig. S1; Fig. 1).

236 Monosaccharides, acetic, malic, and citric acids were detected in root exudates, but the

237 composition and rates differed between Dipterocarp trees (Dipterocapus cornutus and Shorea

238 laevis) and Macaranga trees. The organic acid exudation rates were positively correlated with root

239 surface areas (Fig. 2a) and with root tips, respectively. Root exudation rates of malic and acetic

240 acids by the Dipterocarp trees were greater than the Macaranga trees (Table 2). This contrasts 
241 with the higher monosaccharide exudation of the Macaranga trees (Table 2). There was no

242 significant difference between Dipterocapus cornutus and Shorea laevis, except for in oxalic acid

243 exudation (Table 2).

244 Using the exudation rates and the fine root biomass in the soil profile $(0-10 \mathrm{~cm}$; Tables 1 and

245 2), root exudation rates were transformed into the $C$ fluxes in the in the forest ecosystem (Table

246 4). In the Dipterocarp and Macaranga forests, the $C$ fluxes of multivalent organic acid (citric,

247 malic, and oxalic acids) exudation corresponded to $4.8-6.1 \%$ and $2.1 \%$ of net primary production

248 (NPP) $\left[5.1 \mathrm{~mol} \mathrm{C} \mathrm{m}^{-2}\right.$ month $^{-1}$ (Toma et al., 2000) and $6.2 \mathrm{~mol} \mathrm{C} \mathrm{m}^{-2}$ month $^{-1}$ (Gamo, 2003),

249 respectively] (Table 2). When the published data (Aoki et al., 2012) and those from the present

250 study were included in correlation analysis, the proportions of organic acid exudation relative to

251 NPP were negatively correlated with soil $\mathrm{pH}(\mathrm{KCl})$ (Fig. 2b).

\section{Organic acid sorption reactions}

254 To estimate organic acid sorption in the mineralization kinetics experiment, the data of organic acids sorption and equilibrium concentration were fitted well to a Freundlich equation $\left(R^{2}>0.95\right.$;

Fig. 2; Table 3). Among the four organic acids, the degree of organic acid sorption followed the order: malate $>$ citrate $>$ oxalate $>$ acetate (Fig. 3). There were no differences in sorption of respective organic acids between the soils under Dipterocarp and Macaranga trees (Fig. 3). 
261 We compared mineralization kinetics to assess the specialization of substrate mineralization by

262 rhizosphere and bulk soil microbes. The mineralization rates of both soils varied between

263 substrates and followed the order: malate $>$ citrate, oxalate $>$ acetate, glucose (Fig. 4). The higher

264 mineralization activities in the rhizosphere, compared to the bulk soil, were observed for malate

265 and oxalate in the Dipterocarp soil, but only for malate in the Macaranga soil (Fig. 4). There were

266 no significant differences in mineralization rates of glucose, acetate, and citrate between the

267 rhizosphere and bulk soil fractions under the Dipterocarp and Macaranga trees, respectively (Fig.

268 4).

269 The data of LMWOS mineralization rates were fitted well to the single Michaelis-Menten

270 kinetic equation $\left(R^{2}>0.98\right.$; Fig. 4, Table 4). Michaelis-Menten kinetic parameters $\left(V_{\max }\right.$ and $\left.K_{\mathrm{M}}\right)$

271 describe microbial capacity to mineralize substrate and microbial response to substrate availability,

272 respectively. An increase in malate and oxalate mineralization activity in the Dipterocarp

273 rhizosphere (Fig. 4) was caused by the higher $V_{\max }$ values, compared to the bulk soil (Table 4).

274 An increase in malate mineralization activity in the Macaranga rhizosphere (Fig. 4) was caused

275 by the lower $K_{M}$ values, compared to the bulk soil (Table 4).

277 Carbon fluxes of low molecular weight organic substance mineralization in the rhizosphere

278 Using the bulk density, the volumes of the rhizosphere and bulk soil fractions, the mineralization

279 kinetics (Table 4), we quantified soil C fluxes of LMWOS mineralization to test whether root

280 exudation and rhizosphere $\mathrm{C}$ fluxes are quantitatively important relative to the bulk soil C cycles. 
281 Monosaccharides, malate, and citrate were major substrates for microbial LMWOS

282 mineralization in the bulk soil, while malate accounted for the majority of mineralization C fluxes

283 by in the rhizosphere (Fig. 5). When MRTs of LMWOAs and monosaccharides were calculated

284 by dividing the amount of LMWOS-C in soil solution by mineralization C flux, MRTs were short

285 ranging from $0.2 \mathrm{~h}$ to $5.8 \mathrm{~h}$ for LMWOAs and $10.9 \mathrm{~h}$ to $15.0 \mathrm{~h}$ for monosaccharides, respectively

286 (Table 5). Malate exhibited the shorter MRTs among LMWOSs (Table 5). When the

287 mineralization $\mathrm{C}$ fluxes per soil mass in the rhizosphere were compared to the bulk soil, the

288 rhizosphere effects differed between tree species and between LMWOSs (Table 5). The higher

289 rhizosphere effects were observed for acetate, oxalate, and malate under the Dipterocarp trees,

290 compared to the Macaranga trees (Table 5).

\section{Discussion}

\section{Effects of tree species on root exudation rates}

294 Judging from the fact that LMWOSs are rapidly consumed by microbial uptake and sorption,

295 LMWOS dynamics could be strongly regulated by soil types, substrate charges, and root and

296 microbial activities (Van Hees et al., 2003). On the other hand, LMWOS-C flow in the rhizosphere

297 soil is dependent primarily on composition and amounts of root exudation (Grayston et al., 1996;

298 Aoki et al., 2012). The higher concentration of malate and oxalate in the Dipterocarp rhizosphere

299 relative to the bulk soil suggests that the pool size of organic acids could also vary between tree

300 species, depending on the supply of organic acids (Fig. 1). Consistent with the hypothesis, the 
301 composition and rates of root exudation differ between Dipterocarp and Macaranga trees (Table

302 2; Fig. 5a). The greater rates of organic acid exudation from Dipterocarp trees (Table 2; Fig. 2a)

303 are consistent with the finding that ectomycorrhizal fungi promote mineral weathering by

304 releasing LMWOAs from the hyphae (Jongmans et al., 1997). The lower soil pH under

305 Dipterocarp trees also increases allocation of photosynthate to organic acid exudation (Fig. 2b).

306 Soil $\mathrm{pH}$ is used as a proxy of P deficiency and Al toxicity in our study, because P solubility

307 decreases and $\mathrm{Al}^{3+}$ solubility increases along with soil acidification (Jones, 1998; Fujii et al.,

308 2018). For plants' survival on acidic soils, the high levels of divalent organic acids in the

309 rhizosphere need to be maintained to solubilize recalcitrant $\mathrm{P}$ from $\mathrm{Al}$ or Fe oxides or to detoxify

$310 \mathrm{Al}^{3+}$ (Van Hees et al., 2005). Soil acidification leads to a shift of vegetation towards tree species

311 with capacity to release divalent organic acids from roots, as seen by succession from pioneer tree

312 species to dipterocarp tree species in our study (Fig. 2b). Recently, Mn concentrations in the plant

313 leaf is postulated as a proxy for organic acid exudation activities (Pang et al., 2018; Lambers et

314 al., 2020). This pattern has also been confirmed in pour study, Dipterocarp leaf displays the higher

315 Mn concentrations (1.06 $\left.\mathrm{mg} \mathrm{g}^{-1}\right)$ than Macaranga leaf (0.34 $\left.\mathrm{mg} \mathrm{g}^{-1}\right)$ (Fujii et al., 2020). Both soil

316 acidity and organic acid exudation are considered to increase Mn solubility and root Mn uptake

317 in our study.

319 Rhizosphere effects on organic acid mineralization

320 The rhizosphere is the hotspot of LMWOA cycles (Kuzyakov and Razavi, 2019). This is 
321 supported by the higher concentrations and $\mathrm{C}$ fluxes of malate mineralization, compared to the

322 bulk soil in our study (Figs. 1 and 6). This is primarily due to the substrate inputs via root

323 exudation (Jones et al., 1996; Butler et al., 2003), but microbial potentials to mineralize exudates

324 are also elevated (Fig. 4; Fujii et al., 2013). This is evidenced by the higher $V_{\max }$ values of malate

325 mineralization in the Dipterocarp rhizosphere (Table 4). It has been shown that microbial

326 mineralization potentials (transporter activity) could vary, depending on C sources that microbes

327 have grown on (Jones et al., 1996). Microbial community grown on malate could have the higher

328 activity of malate transporter that takes the malate into the cell, compared to microbial community

329 grown without malate (Jones et al., 1996). In our study, root exudation of malate might increase

330 malate preference and mineralization activity of rhizosphere microbial community (Table 4). This

331 contrasts with the low availability of organic acids in the volcanic soils leading to the low

332 microbial mineralization activities (Fujii et al., 2019). Both higher substrate availability in the

333 rhizosphere and the associated higher mineralization activities of microbes shape the hotspots of

334 organic acids in the Dipterocarp rhizosphere (Fig. 5).

336 Compound-specific rhizosphere effects

337 Tropical trees require rhizosphere processes to acquire $\mathrm{P}$ and protect roots in the highly weathered

338 and acidified soils (Fujii et al., 2018). Due to the highest sorption of malate and its shortest MRTs

339 among organic acids (Fig. 3; Table 5), the efficacy of exuded malate on P mobilization and $\mathrm{Al}^{3+}$

340 detoxification in the rhizosphere could be reduced (Jones et al., 1996). There should occur the 
341 mechanisms to maintain the pool size of malate in rhizosphere soil solution (Van Hees et al.,

342 2005b). This could be partly accounted for by the higher rates of malate exudation from the

343 Dipterocarp roots (Table 2), but malate-C inputs by root exudation can not account for the whole

344 C fluxes of malate mineralization in the rhizosphere (Figs. 5 and 6). This indicates that malate

345 could be supplied by the other sources as well as root exudation. Malate could be produced as

346 microbial metabolites in organic matter degradation pathways such as tricarboxylic acid cycle

347 (Van Hees et al., 2005). Malate as well as oxalate can also be released by fungi in lignin oxidation

348 by manganese peroxidase, where malate chelates $\mathrm{Mn}^{3+}$ and complex of $\mathrm{Mn}^{3+}$-malate works as

349 diffusible oxidant (Hatakka, 2001). The exuded glucose or citrate might be transformed into

350 malate and released by fungi to decompose lignin or recalcitrant organic matter (Plassard and

351 Fransson, 2009). Organic acid exudation from roots increases at lower $\mathrm{pH}$ for P solubilization and

$352 \mathrm{Al}^{3+}$ detoxification (Fig. 2b) and for degradation of lignin-rich dipterocarp litters (Fujii et al.,

353 2020). These rhizosphere microbial activities, as well as root exudation, could increase malate

354 turnover and affect $\mathrm{C}$ fluxes at soil profile and ecosystem scales.

\section{Conclusions}

357 Root exudation rates differ between tree species. Malate was a dominant organic acid exuded

358 from Dipterocarp roots, while monosaccharides were dominant exudates of Macaranga trees.

359 Organic acid exudation increased with increasing root surface area and with decreasing soil pH.

360 Root exudation of malate increases malate mineralization activities by rhizosphere microbes, but 
361 malate budgets suggest that malate rhizosphere microbes are another malate producer. Tree

362 species affects both root exudation composition and rhizosphere microbes that increase malate

363 production at lower soil $\mathrm{pH}$, likely for phosphorus solubilization, aluminum detoxification, and

364 lignin degradation.

365

366 Acknowledgments

367 We thank Dr. Patrick A.W. Van Hees for teaching techniques of ${ }^{14} \mathrm{C}$ tracer experiments. We also

368 thank the editor and anonymous reviewers for their helpful suggestions and comments on the

369 manuscript. A part of the results has been presented in EGU 2021

370 (https://meetingorganizer.copernicus.org/EGU21/session/38709).

371 Data availability statement: The data of soil solution composition, organic acid sorption, and

372 mineralization kinetics are available from the Dryad Digital Repository:

373 https://doi.org/10.5061/dryad.2z34tmpmg (K. Fujii)

374 Competing interests: There are no completing interests.

375 Author contributions K.F. and C.H. designed the study. K.F. and S. established the field experiment and discussed the results. K.F. wrote the manuscript.

\section{References}

Aoki M, Fujii K, Kitayama K (2012) Environmental control of root exudation of low-molecular- 
weight organic acids in tropical rainforests. Ecosystems, 15, 1194-1203.

381 Blakemore LC, Searle PL, Daly BK (1987) Methods for chemical analysis of soils. NZ Soil Bureau Scientific Report, 80.

Burney CM, Sieburth JMcN (1977) Dissolved carbohydrates in seawater. II. A spectrophotometric procedure for total carbohydrate analysis and polysaccharide estimation. Marine Chemistry, $5,15-28$.

Butler JL, Williams MA, Bottomley PJ, Myrold DD (2003) Microbial community dynamics associated with rhizosphere carbon flow. Applied and Environmental Microbiology, 69, 6793-6800.

Dijkstra FA, Carrillo Y, Pendall E, Morgan JA (2013) Rhizosphere priming: a nutrient perspective. Frontiers in Microbiology, 4, 216.

Fujii K, Aoki M, Kitayama K (2013) Biodegradation of low molecular weight organic acids in $142-148$.

Fujii K, Shibata M, Kitajima K, Ichie T, Kitayama K, Turner BL (2018) Plant-soil interactions $149-160$.

Fujii K, Hayakawa C, Inagaki Y, Ono K (2019) Sorption reduces the biodegradation rates of multivalent organic acids in volcanic soils rich in short-range order minerals. Geoderma, 333, $188-199$. 
400 Gamo M (2003) Measurements of net ecosystem production by eddy correlation method. The Tropical Forestry, 57, 7-16.

Giesler R, Lundström US (1993) Soil solution chemistry-the effects of bulking soil samples and spatial variation. Soil Science Society of America Journal, 57, 1283-1288.

404

Grayston SJ, Vaughan D, Jones D (1996) Rhizosphere carbon flow in trees, in comparison with annual plants: the importance of root exudation and impact on microbial activity and nutrient availability. Applied Soil Ecology, 5, 29-56.

Hatakka A (2001) Biodegradation of lignin. In: Hofrichter, M., Steinbüchel, A. (Eds.), Biopolymers: biology, chemistry, biotechnology, applications, vol 1. Lignin, humic substances and coal. Wiley VCH, Weinheim, pp 129-180.

Johnson KM, Sieburth JMcN (1977) Dissolved carbohydrates in seawater. I. A precise spectrophotometric analysis for monosaccharides. Marine Chemistry, 5, 1-14.

Jones DL (1998) Organic acids in the rhizosphere -a critical review. Plant and Soil, 205, 25-44.

Jones DL, Brassington DS (1998) Sorption of organic acids in acid soils and its implications in the rhizosphere. European Journal of Soil Science, 49, 447-455.

Jones DL, Prabowo AM, Kochian LV (1996) Kinetics of malate transport and decomposition in acid soils and isolated bacterial populations: the effect of microorganisms on root exudation of malate under Al stress. Plant and Soil, 182, 239-247.

Jones DL, Dennis PG, Owen AG, Van Hees PAW (2003) Organic acid behavior in soils misconceptions and knowledge gaps. Plant and Soil, 248, 31-41. 
Jones DL, Hodge A, Kuzyakov Y (2004) Plant and mycorrhizal regulation of rhizodeposition. New Phytologist, 163, 459-480.

Jongmans AG, Van Breemen N, Lundström U, Van Hees PAW, Finlay RD, Srinivasan M, Olsson M (1997) Rock-eating fungi. Nature, 389(6652), 682.

Kuzyakov Y, Razavi BS (2019) Rhizosphere size and shape: Temporal dynamics and spatial stationarity. Soil Biology and Biochemistry, 135, 343-360.

Lambers, H. et al. (2020) Leaf manganese concentrations as a tool to assess belowground plant functioning in phosphorus-impoverished environments. Plant and Soil, 1-19. fungi. Fungal Biology Reviews, 23, 30-39. solution-a review. Geoderma, 99, 169-198. 
Ström L, Owen AG, Godbold DL, Jones DL (2001) Organic acid behavior in a calcareous soil: sorption reactions and biodegradation rates. Soil Biology and Biochemistry, 33, 2125-2133.

Toma T, Matius P, Kiyono Y, Watanabe R, Okimori Y (2000) Dynamics of burned lowland dipterocarp forest stands in Bukit Soeharto, East Kalimantan. In Rainforest Ecosystems of East Kalimantan (pp. 107-119). Springer, Tokyo.

Van Hees PAW, Dahlen J, Lundström US, Boren H, Allard B (1999) Determination of low 
Table legends

462

463 Table 1 Aboveground biomass and physicochemical properties of tropical forest soils

464

Table 2 Root traits and exudation rates of Dipterocarp and Macaranga trees

466

Table 3 Freundlich isotherm parameters, sorption capacity $(k)$ and sorption intensity $(1 / n)$, to describe organic acid sorption in soil

469

Table 4 Michaelis-Menten kinetic parameter values of the rhizosphere and bulk soil fractions

Table 5 Soil solution pool, mineralization flux, and mean residence time of organic acids in the 
Figure legends

482

Fig. 1 Concentrations of (a) low molecular weight organic acids and (b) monosaccharides in

rhizosphere and bulk soil solutions. Bars indicate standard errors $(N=5)$. The statistical

$0.05)$ or n.s. (not significant).

Fig. 2 (a) Relationship between root surface area and root exudation rate of organic acids,

(b) relationship between root exudation of organic acids relative to net primary production

(NPP). Acetate, oxalate, malate, and citrate were counted in Fig. 2a, while oxalate, malate, and

Fig. 3 Concentration-dependent sorption of citrate, oxalate, malate, and acetate in soils. 
499 glucose in soils. Symbols denote experimental points, while the curves represent Michaelis-

500 Menten isotherms fitted to the experimental data. Bars indicate standard errors $(N=5)$.

Fig. 5 (a) Basal area-weighted mean root exudation rates of low molecular weight organic substances (LMWOSs) and (b) C flux of LMWOS mineralization in the rhizosphere soil $(P<0.05)$ between sites was tested by ANOVA.

Fig. 6 Malate-C pools and fluxes of root exudation and mineralization in the rhizosphere and bulk soil fractions. The data of root exudation rates (Fig. 5), mineralization C flux (Table 5) were used. Supplementary file Fig. S1 (a) Concentrations of low molecular weight organic substances in rhizosphere and bulk soil solutions and (b) sum of low molecular weight organic acids. Bars indicate standard errors $(N=5)$. The statistical significance of differences between rhizosphere and bulk soil solutions was indicated by $*(P<0.05)$ or n.s. (not significant). 
Figures

(a) Organic acids (b) Monosaccharides

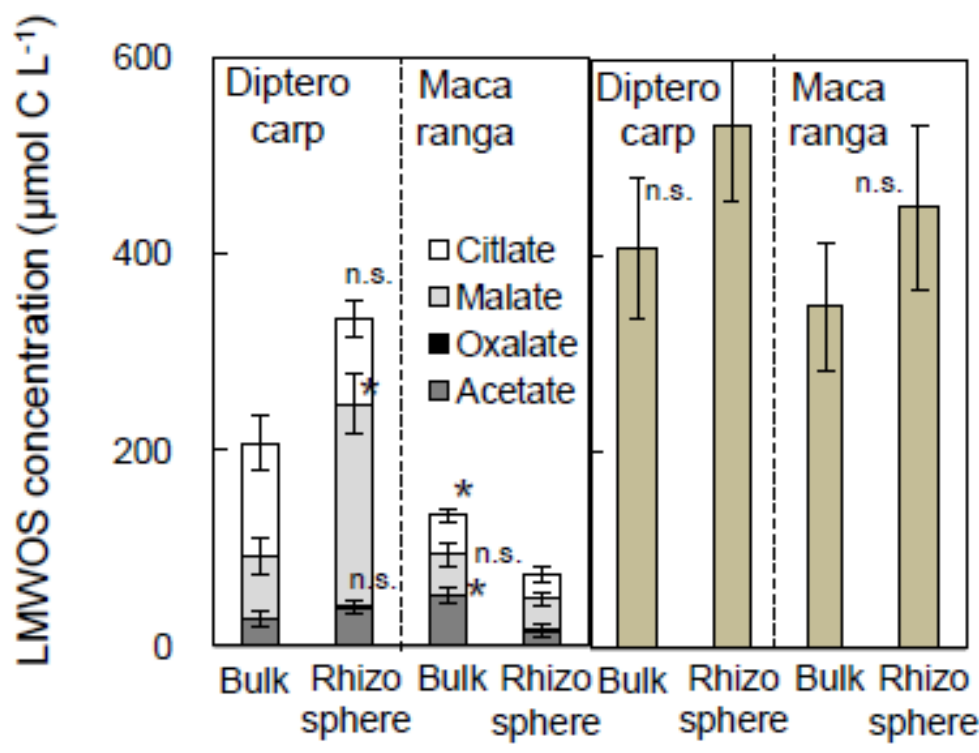

Figure 1

Concentrations of (a) low molecular weight organic acids and (b) monosaccharides in rhizosphere and bulk soil solutions. Bars indicate standard errors $(\mathrm{N}=5)$. The statistical significance of differences between rhizosphere and bulk soil solutions was indicated by * $(P<0.05)$ or n.s. (not significant). 

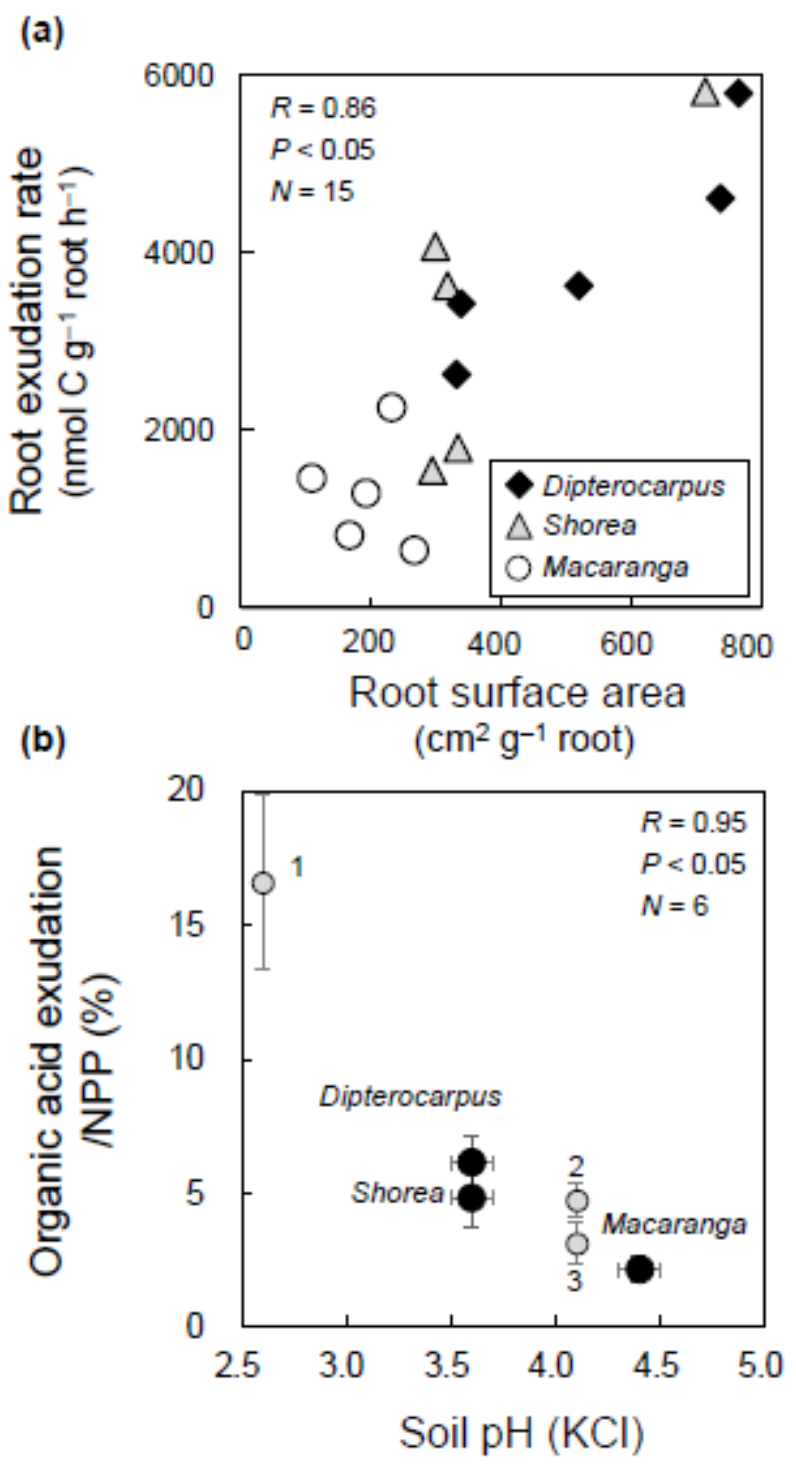

Figure 2

(a) Relationship between root surface area and root exudation rate of organic acids, (b) relationship between root exudation of organic acids relative to net primary production (NPP). Acetate, oxalate, malate, and citrate were counted in Fig. $2 a$, while oxalate, malate, and citrate were counted in Fig. $2 b$ to compare with the previous study [1, $2=$ tropical montane forest, $3=$ tropical forest (Aoki et al., 2012)]. Bars indicate standard errors $(N=5)$. Root 


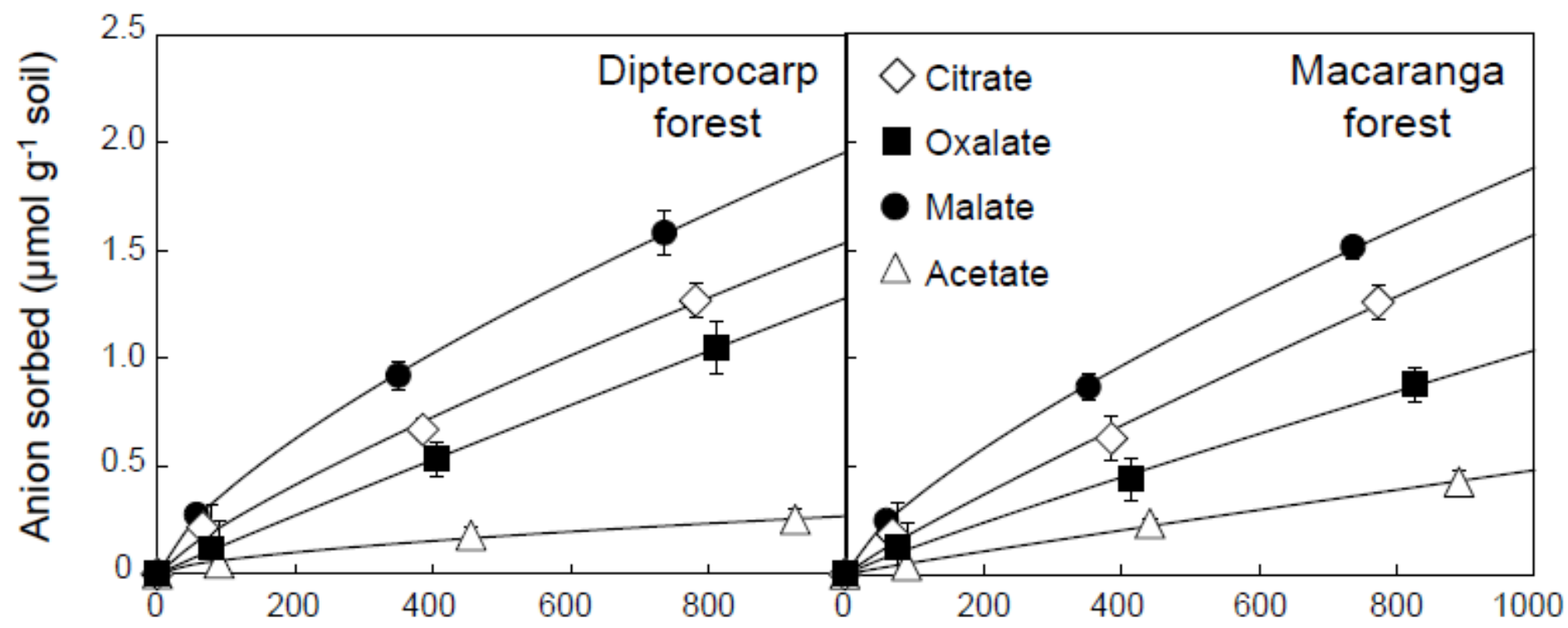

Equilibrium solution concentration $(\mu \mathrm{M})$ Equilibrium solution concentration $(\mu \mathrm{M})$

Figure 3

Concentration-dependent sorption of citrate, oxalate, malate, and acetate in soils. Symbols denote experimental points, while the curves represent Freundlich sorption isotherms fitted to the experimental data. Bars indicate standard errors $(\mathrm{N}=5)$. 


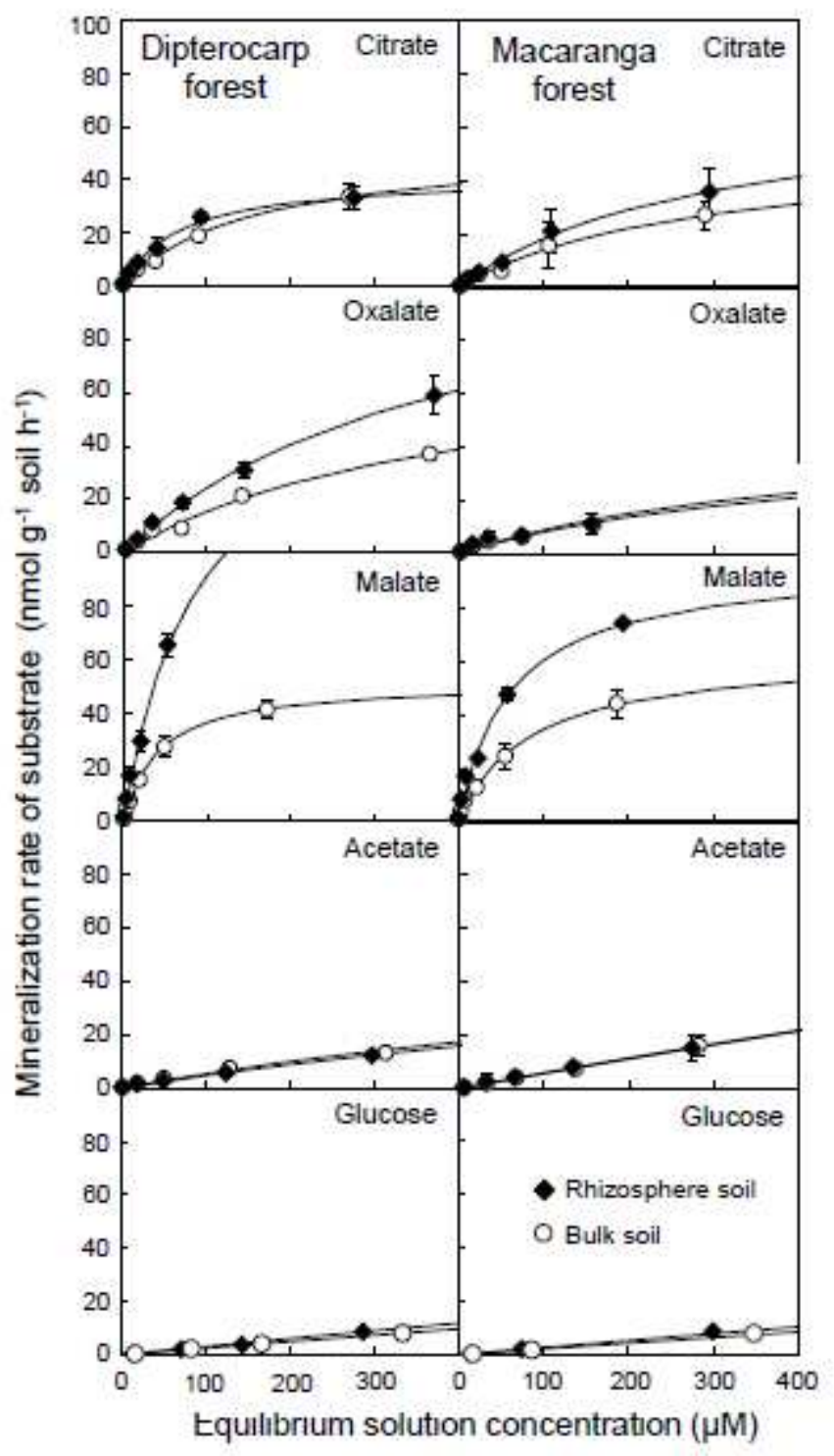

Figure 4

Concentration-dependent mineralization of citrate, oxalate, malate, acetate, and glucose in soils. Symbols denote experimental points, while the curves represent Michaelis- Menten isotherms fitted to the experimental data. Bars indicate standard errors $(\mathrm{N}=5)$. 


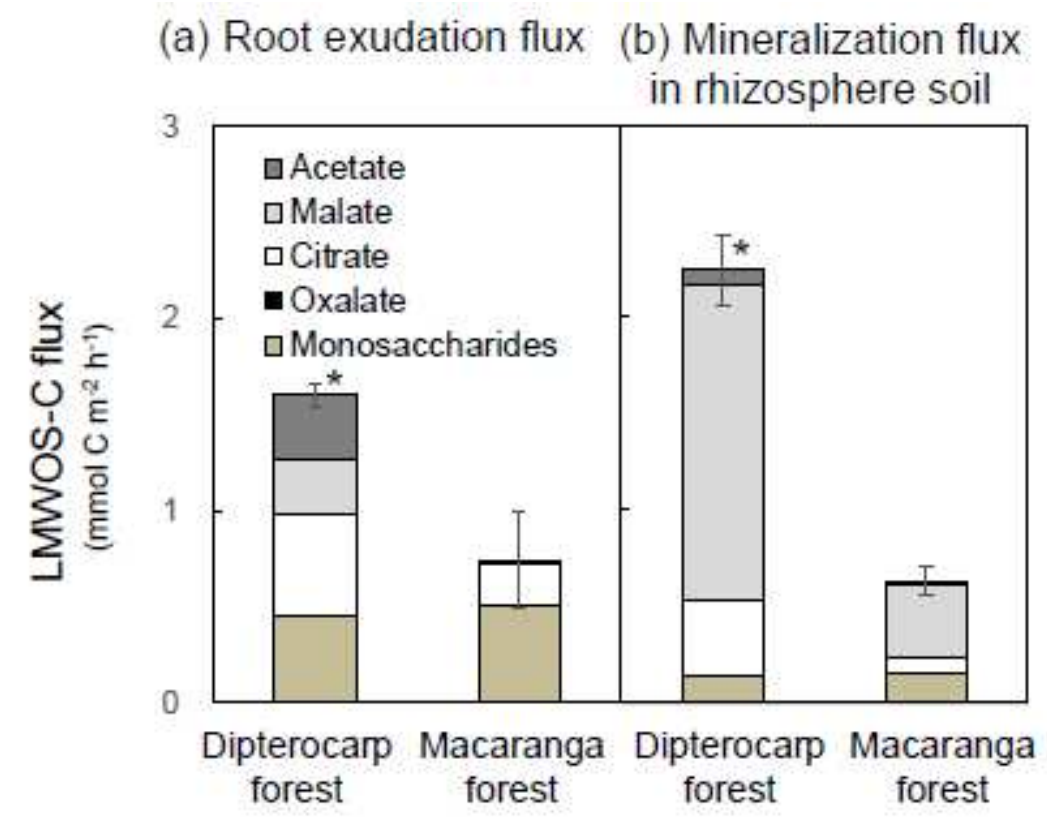

Figure 5

(a) Basal area-weighted mean root exudation rates of low molecular weight organic substances (LMWOSs) and (b) $\mathrm{C}$ flux of LMWOS mineralization in the rhizosphere soil fraction. Bars indicate standard errors for the sum of LMWOSs $(N=5)$. Significant difference $(P<0.05)$ between sites was tested by ANOVA. 
Dipterocarp forest

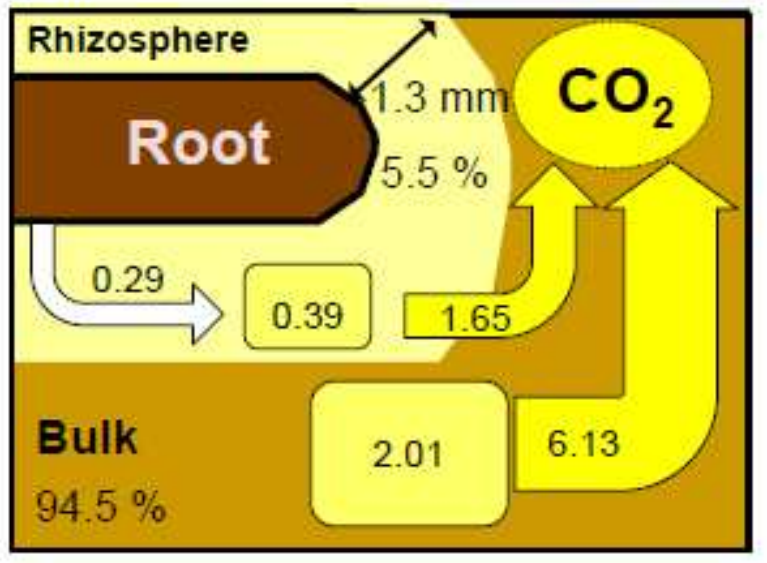

Macaranga forest

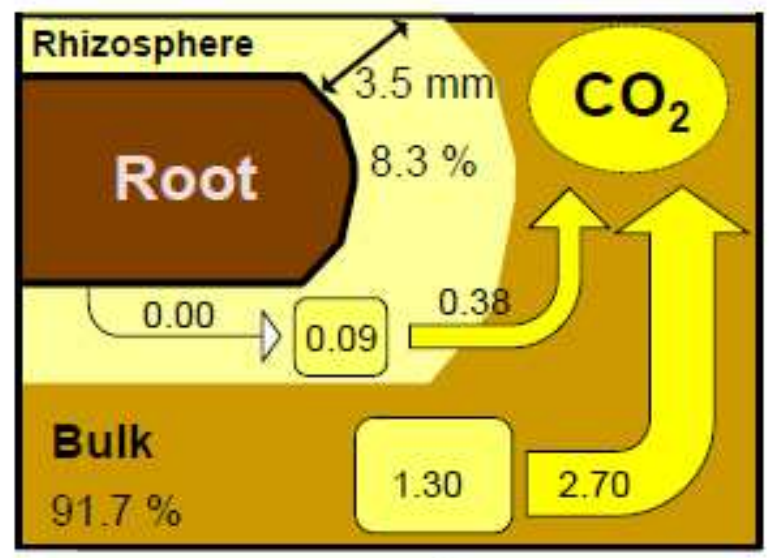

$\square$

C pool

(mmol C m${ }^{-2}$ )

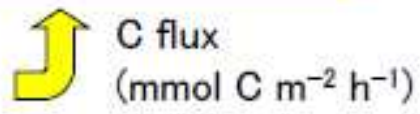

Figure 6

Malate $\mathrm{C}$ pools and fluxes of root exudation and mineralization in the rhizosphere and bulk soil fractions The data of root exudation rates (Fig 5 mineralization C flux (Table 5 were used

\section{Supplementary Files}

This is a list of supplementary files associated with this preprint. Click to download.

- Tables.pdf

- SupplementaryFig1.pdf 